\title{
Toward an Understanding of the Link between Work-Family Enrichment and Individual Health
}

\author{
Misti Stoddard \\ Susan R. Madsen \\ Utah Valley State College
}

\begin{abstract}
Decades of research have focused on the negative impact multiple roles can have on workplaces and homes. However, little attention has been given to the individual benefits that may result from simultaneous participation in these roles. Fortunately, a recent construct, work-family enrichment, has emerged which considers positive influences that one domain (i.e., work, family) has on another. This study utilized the 18item Carlson, Kacmar, Wayne, and Grzywacz, (2006) enrichment scale and the Madsen, John, and Miller (2005) adapted individual health scale to study correlations and linkages among health constructs (i.e., mental-emotional and physical) and the various dimensions of work-family enrichment.
\end{abstract}

\section{Introduction}

Work-family issues have been under the microscopes of researchers over the past few decades. There is ongoing evidence suggesting that a lack of work and family balance leads to work-family conflict (Grzywacz \& Bass, 2003; Major, Klein, \& Ehrhart, 2002). Hence, researchers have focused on the negative aspects of simultaneously participating in work and family roles. Research (e.g., Greenhaus \& Buetell, 1985) suggests that through dual participation in work and family roles, an individual's life will become stressed and depleted. The resulting conflict has been found to negatively influence employee health and well-being (Frone, 2000; Frone, Russell, \& Cooper, 1997; Madsen, John, \& Miller, 2005; Major et al., 2002) and organizational performance (Allen, Herst, Bruck, \& Sutton, 2000). Understandably, attention has primarily focused on the time-, stress-, and behavior-based spillover between these roles as well as the work-to-family and family-to-work interference (Carlson, Kacmar, \& Williams, 2000; Greenhaus \& Buetell, 1985). Therefore, decades of research have focused on the negative impact multiple roles have had on workplaces and homes, while little attention has been given to the individual benefits that may result from simultaneous participation in these roles.

Researchers (e.g., Carlson, Kacmar, Wayne, \& Grzywacz, 2006; Greenhaus \& Powell, 2006) are beginning to shift the focus from these negative aspects to discovering the positive potential available to those who choose to juggle both work and family roles. Coming to the rescue of those enjoying a full and joyful life by combining work and family roles, an emerging body of research is now showing the benefits derived from multiple role participation. This research provides evidence that individuals can experience various benefits and an increase in the quality of life (Carlson et al., 2006; Greenhaus \& Powell, 2006). This new construct is called work-family enrichment. 
Greenhaus and Powell (2006) have recently conceptualized this construct and defined it as the extent to which experiences in one role improve the quality of life in the other role. Work-family enrichment occurs when resources gained in one role either directly improve performance in the other role (instrumental) or indirectly through the influence on positive affect (affective) (Carlson et al., 2006). Through the instrumental path, resources are directly transferred from one role to another. For example, a skill acquired through work is transferred and applied at home, resulting in improved interaction with family members. The affective pathway focuses on positive moods and emotions derived from experiences obtained through work and family roles.

The Department of Labor is calling "flexibility and family" one of the three major challenges facing workers and employers in the 21st century (U.S. Department of Labor, 1999). An increasing number of dual career and single parents are entering the workforce, while the care giving needs of the aging population are rising. These trends provide new challenges and responsibilities for men and women to unify work and family commitments (Grzywacz, 2000). Additionally, the Families and Work Institute reported that work-life balance was ranked among one of the most important factors considered by individuals in accepting new positions (Parasuraman \& Greenhaus, 1997). In order for employers to attract and retain the most capable human resources, attention must focus on the relationships among the interdependencies of the workfamily interface and a variety of constructs, including individual health. Understanding the benefits of combining work and family will assist men and women in their quests for greater satisfaction in life. It will also help employers understand how to cultivate greater job satisfaction among their employees and improve individual and organizational performance.

\section{Theoretical Framework}

The theoretical framework for work-family enrichment focuses on the generation and application of resources gained through participating in work and family roles that, when applied, result in improved performance or positive affect (mood) in the other role (Carlson et al., 2006). There are three main components that outline the theoretical framework of work-family enrichment: 1) work-family enrichment directions and dimensions, 2) resources generated in work and family roles, and 3) paths that promote work-family enrichment in each role (Greenhaus \& Powell, 2006).

First, work-family enrichment is conceptualized as being multidimensional. Work can provide resource gains that enhance performance in the family domain, or family can provide resources gains that improve performance in the work domain (Carlson et al., 2006). It is concerned with the resources gained through work experience that are transferred to family life resulting in either increased performance or positive affect in the family role, and it looks at family experiences that translate to increased performance or affect at work. In addition to the directions (i.e., work-to-family enrichment (WFE) and family-to-work enrichment (FWE)), Carlson et al. (2006) further investigated three dimensions for each direction of enrichment. These dimensions were defined by Carlson et al. (2006) as follows: 
1. Work-to-family direction:

a. Development occurs when involvement in work leads to the acquisition or refinement of skills, knowledge, behaviors, or ways of viewing things that help and individual be a better family member.

b. Affect is defined as a positive emotional state or attitude which results when involvement in work helps the individual be a better family member.

c. Capital occurs when involvement in work promotes levels of psycho-social resources such as a sense of security, confidence, accomplishment, or self-fulfillment that helps the individual be a better family member.

2. Family-to-work direction:

a. Development occurs when involvement in family leads to the acquisition or refinement of skills, knowledge, behaviors or ways of viewing things that help an individual be a better worker.

b. Affect occurs when involvement in family results in a positive emotional state or attitude which helps the individual be a better worker.

c. Efficiency occurs when involvement with family provides a sense of focus or urgency which helps the individual be a better worker.

Second, Greenhaus and Powell (2006) describe a resource as "an asset that may be drawn on when needed to solve a problem or cope with a challenging situation" (p. 80). Greenhaus and Powell (2006) have identified and defined five types of resources that have the ability to promote work-family enrichment: skills and perspectives, psychological and physical resources, social-capital resources, flexibility, and material resources. Skills and perspectives refer to cognitive and task-related interpersonal skills. Perspective deals with handling situations and respecting differences, while skills focus on coping and multitasking abilities obtained through role experience. Psychological resources include self-esteem and self-efficacy, as well as positive emotions about the future. Physical resources refer to increasing energy, mental sharpness and stamina. Social-capital resources are interpersonal relationships developed at work or through family participation that help individuals achieve their goals. Flexibility refers to an individual's ability to determine the timing, pace, and location where role requirements are met. Material resources include money and gifts obtained from work and family roles. Work-family enrichment occurs when resources generated through participation in Role A (i.e., work or family) are applied and promote either increased performance or positive affect in Role B (i.e., work or family), thus increasing the quality of life in Role B.

Third, Greenhaus and Powell (2006) found that resources promote work-family enrichment primarily through two different paths: instrumental and affective (see Figure 1). The instrumental pathway is illustrated through prior research revealing that employees believe their family involvement has prepared them with resources necessary to handle co-workers or that these resources have increased their ability to perform on the job (Carlson et al., 2006; Crouter, 1984). For example, managers who learn greater communication skills through work experience are able to apply this skill with their families, thus decreasing conflict and increasing the quality of family life. In 
the instrumental path, resource gains at work have a direct effect on the other role (family), and the application results in improved performance in that role.

Figure 1. Work-family Enrichment Resources and Paths

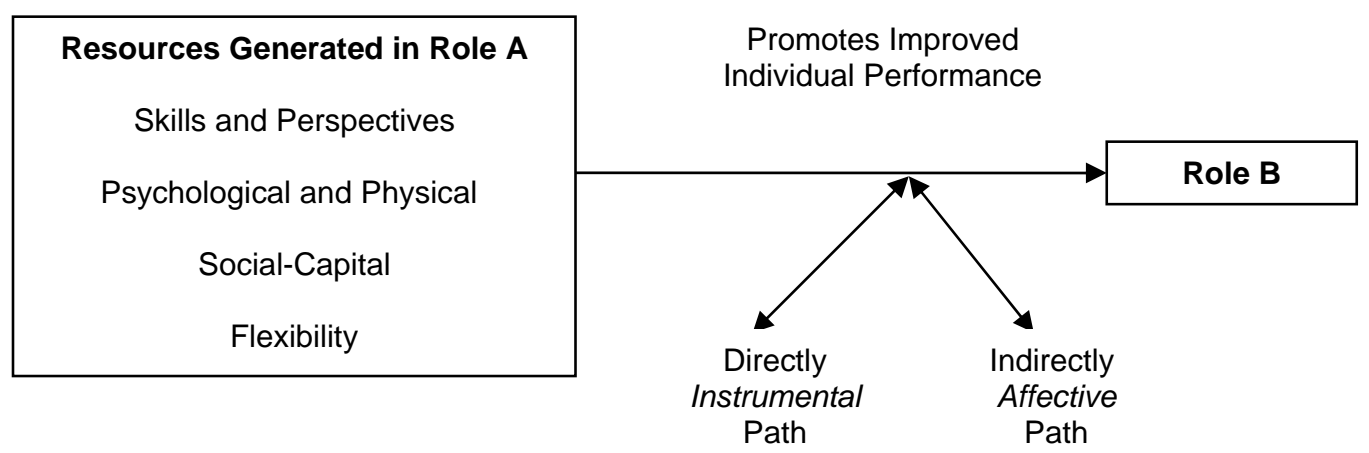

The affective path promotes work-family enrichment indirectly through influence on moods and emotions resulting from role participation (Carlson et al., 2006; Greenhaus \& Powell, 2006). More specifically, as individuals gain greater resources through ongoing participation in one role (i.e., work or family) their mood or emotional state in that role has increased. This can aid their performance in the other role (Greenhaus \& Powell, 2006). For example, as employees receive promotions their emotional state or mood at work increases, and this positive affect will likely carry over to home life, thus increasing the quality of performance at home (Carlson et al., 2006). Therefore, the affective path promotes positive affect in the same role in which it was generated (positive mood at work) and results in an increased performance in the other role (greater positive mood at home).

\section{Literature Review}

Although work-family enrichment is a new construct, researchers have previously examined the positive effects of work and family roles. These constructs are positive spillover (Crouter, 1984; Grzywacz, 2000), facilitation (Grzywacz, 2002) and enhancement (Sieber, 1974). Positive spillover refers to experiences in one domain that transfer to another domain, causing the two domains to be similar (Carlson et al., 2006; Edwards \& Rothbard, 2000). Facilitation is defined as gains obtained through experience in one domain that enhances the functioning of the other domain (Carlson et al., 2006; Grzywacz, 2002). Finally, enhancement focuses on the benefits individuals acquire and the chance these benefits will have an outstanding effect on other roles in life (Carlson et al., 2006; Sieber, 1974). Throughout the literature these constructs have been used interchangeably to describe the positive associations between work and family (Carlson et al., 2006; Frone, 2003). A review of this literature reveals interesting relationships between the positive side of the work-family interface and various constructs. 
Several studies have found relationships between work-family facilitation (work-to-family and family-to-work) and individual health (mental, emotional, and physical). Most of the findings suggest facilitation contributes to increased physical and mental health. Specifically, Grzywacz and Bass (2003) found that work-family facilitation was associated with lower risk of mental illness, depression, and problem drinking. In fact, each unit increase in family-to-work facilitation was associated with a 15 percent decrease of reported depression and a 38 percent decrease in reported problem drinking. Hanson, Hammer and Colton (2006) discovered that the more resources available to an individual at home, the higher their level of mental health. Grzywacz (2000) also found that positive spillover was related to lower levels of problem drinking and was associated with better self-reported mental health. Interestingly, even in the 1980s, Baruch and Barnett (1986) stated that "empirical evidence and theory are converging to suggest that, for women as well as men, involvement in a multiplicity of roles yields a net gain of benefits over costs with respect to both physical and mental health" (p. 578). In other words, participating in multiple roles may have additive effects on an individual's physical health.

Studies have also found relationships between work-family conflict and adverse health outcomes. Most of these findings suggest the opposite of work-family enrichment-that conflict contributes to a decrease in physical and mental health. For example, Frone et al. (1997) and Frone, Russell, and Barnes (1996) reported that conflict is related to increased levels of depression, poor physical health, hypertension and heavy alcohol consumption. Major et al. (2002) also found significant correlations between work-family conflict and somatic complaints, as well as depression. Madsen, John, and Miller (2005) also found a significant relationship between higher employee perceptions of both workto-family and family-to-work conflict and their own perceptions of personal mental and physical health. In combination these studies present persuasive evidence that both work-family enrichment and work-family conflict are related either favorably (enrichment) or unfavorably (conflict) to health outcomes.

Several studies have examined the relationships between the work-family interface (positive and negative) and gender. Some researchers have found no significant differences across gender (Frone et. al, 1996; Frone et al., 1997; Grzywacz 2000). However, other studies (e.g., Grzywacz \& Marks 2000; Rothbard 2001) have shown that women report a higher positive emotional reaction from the work-to-family direction than men. Additionally, work-to-family conflict research has found no significance in relation to conflict and gender (Frone et al., 1996; Frone et al., 1997). Therefore, the findings tend to be inconsistent. In regards to demographics, a study conducted by Grzywacz and Marks' (2000) research found interesting gender characteristics in relation to workto-family positive spillover. Their findings show that younger men experience less positive spillover than older men from both the work-to-family and family-to-work direction, and that younger women experience greater positive spillover form the workto-family direction than older women. In addition, this study reports that men with children experience a higher level of positive spillover from the work-to-family direction than men without children. An examination of work-family conflict literature and 
demographics reveal employee age is weakly yet significantly related to work-to-family conflict (Madsen et al., 2005). However, little research has been reported on possible relationships between work-family enrichment and age.

\section{Purpose and Hypotheses}

The purpose of this current study is threefold: 1 ) to examine the degree to which employees at retail establishments perceive work-family enrichment in their lives; 2 ) to contrast these perceptions with participants' perceptions of their own mental, physical and overall health; and 3 ) to investigate the relationship between work-family enrichment perceptions and the following employee demographics: gender, number of children, marital status, work status, employee age, and education level. The proposed hypotheses are as follows:

Hypothesis 1a-i: Overall health, mental-emotional health, and physical health will be positively related to perceived (a) WFE, (b) FWE, (c) work-to-family development, (d) work-to-family affect, (e) work-to-family capital, (f) family-towork development, (g) family-to-work affect, and (h) family-to-work efficiency.

Hypothesis 2: The perceived enrichment felt from family-to-work will be significantly higher than work-to-family.

As outlined previously, in addition to the two proposed hypotheses, we were also interested in exploring the various relationships between the demographics listed previously and each of the study variables (work-family enrichment and health).

\section{Research Methods}

The sample for this research study included sales employees from two different branches of a large retail business within the state of Utah. Both branch managers distributed the survey and an approved letter of consent to employees at a weekly sales meeting where most were in attendance. The employees completed the survey and personally deposited it into a large, provided envelope. A key contact at each branch immediately sealed the envelope after all the surveys were collected. A researcher picked up the envelope the following week.

Two scales were used to measure the variables of this study-work-family enrichment and health. Both used a 5-point scale where " 1 " was strongly disagree and "5" was strongly agree. First, an 18-item work-family enrichment scale, recently developed and validated by Carlson et al. (2006), was used to measure the degree of work-family enrichment. This multidimensional measure of the work-family enrichment scale measured resource gains in both directions (work-to-family and family-to-work) of the work-family interface. With each direction, scale items also included the three dimensions outlined previously (i.e., development, affect, and capital/efficiency). Since resource generation is essential to the work-family enrichment process, Carlson et al. (2006) included resource gains as outlined by Greenhaus and Powell (2006). This 
included the instrumental (i.e., skills, self efficacy) and affective (i.e., moods and attitudes) paths. Carlson et al. (2006) reported, "Ultimately, we produced a list of 14 potential resource gains through which enrichment might occur including perceptions by others, behavior, skills, knowledge, perspectives, time, energy, resources, support, selffulfillment, self-esteem/self-efficacy, moods and attitudes" (p. 9). As previously mentioned, work-family enrichment is different from other constructs that examine the positive side of the work-family interface in the way it requires a transfer of resources gained in one role that results in improved performance in the other role. Therefore, Carlson et al. (2006) developed this scale to capture the resource, application and positive result. For example, the first question asks, "My involvement in work helps me to understand different viewpoints and this helps me be a better family member." In order to strongly agree to this item the participant must first agree that work involvement helps to understand different viewpoints, and then agree that these different viewpoints transfer to home life making that participant a better family member. The Cronbach's alpha for the Carlson et al. (2006) scale was .92 for the nine work items, .86 for the nine family items, and the full scale (all 18 items) was .92. This indicates strong internal consistency. Reliability in this study was similar to Carlson et al.'s with overall workfamily enrichment (alpha=.91), work-to-family items (alpha=.89) and family-to-work items (alpha=.88).

The second scale was an adapted 7-item health instrument developed by Madsen, John, and Miller (2005). It was used to measure overall health perceptions (i.e., mental, emotional, physical). It was originally adapted from subscales within Hanpachern's (1997) Revised Margin in Life instrument (Madsen et al., 2005). The Cronbach's alpha of this scale in this study was .85. Six demographic questions were added to the final instrument. These included work status, age, gender, marital status, education level and number of children.

A number of statistical tests were used to analyze the results of this study. First, frequencies, means, and standard deviations were used to describe the sample (demographics) and general results. Pearson correlations were used to test magnitude and direction of the relationship for the hypotheses, while t-tests were used to compare statistical means. The primary method of analysis for demographics was a linear multiple regression. This was useful in determining the relationships between the primary constructs (work-family enrichment and health constructs) and the combination of applicable demographic (predictor) variables for the sample.

\section{Results}

Of the 190 distributed questionnaires, 119 were returned; 116 were deemed usable and were included in the study results for a return rate of 61 percent. Three returned surveys were too incomplete to use. Selected demographic results were gathered and compiled (see Table 1). In summary, most employees surveyed were male (74\%), worked fulltime (84\%), had no children (41\%) and were either attending college presently or had some college experience (47\%). 
Table 1. Demographic Frequencies of the Sample

\begin{tabular}{|l|l|l|l|}
\hline Demographic & Category & Frequencies & $\%$ \\
\hline Sample & Total number & 116 & 100 \\
\hline Gender & Male & 86 & 74.1 \\
& Female & 30 & 25.9 \\
\hline Age range & Less than 21 & 07 & 6.0 \\
& $21-30$ & 66 & 56.8 \\
& $31-40$ & 20 & 17.2 \\
& $41-54$ & 16 & 14 \\
& $55+$ & 07 & 6.0 \\
\hline Marital status & Single & 24 & 20.7 \\
& Married & 91 & 78.4 \\
& Divorced & 01 & .9 \\
\hline Highest educational & High School & 09 & 7.7 \\
level & Some College & 54 & 46.6 \\
& Associate Degree & 31 & 26.7 \\
& Bachelor Degree & 19 & 16.4 \\
& Masters/PhD & 03 & 2.6 \\
\hline Number of children & 0 & 48 & 41.4 \\
& 1 & 20 & 17.2 \\
& 2 & 15 & 12.9 \\
& 3 & 15 & 12.9 \\
& $4+$ & 18 & 15.6 \\
\hline Work Status & Full-Time & 97 & 83.6 \\
& Part-Time & 04 & 3.5 \\
& Three-quarter Time & 15 & 12.9 \\
\hline
\end{tabular}

Overall, employees in this study perceived themselves as having moderate levels of work-family enrichment with a statistical mean (M) of 3.45 on the 5-point scale described. In addition, employees gain a statistically significant higher positive emotional state (affect) from family involvement $(M=3.92)$ than from work involvement $(M=2.72)$ and acquire more skills, knowledge and behaviors from family involvement $(M=3.68)$ than from work involvement $(M=3.46)$. Employees have a moderate sense of focus or urgency $(M=3.59)$ from family that helps them be a better worker. These employees have strong overall health $(M=4.16)$, with significantly stronger mental/emotional health $(M=4.23)$ than physical health $(M=4.04)$ (see Table 2). Additionally, mean levels of family-to-work enrichment $(M=3.73)$ were statistically higher than work-to-family mean levels $(M=3.17)$. 
Table 2. Constructs, Means, and Standard Deviations

\begin{tabular}{|c|c|c|}
\hline Variable & $\mathbf{M}$ & SD \\
\hline Enrichment & 3.45 & .63 \\
\hline Work-to-family enrichment (WFE) & 3.17 & .72 \\
\hline Family-to-work enrichment (FWE) & 3.73 & .72 \\
\hline Work-to-family development (WFD) & 3.46 & .79 \\
\hline Work-to-family affect (WFA) & 2.72 & .92 \\
\hline Work-to-family capital (WFC) & 3.32 & .92 \\
\hline Family-to-work development (FWD) & 3.68 & .82 \\
\hline Family-to-work affect (FWA) & 3.92 & .92 \\
\hline Family-to-work efficiency (FWEF) & 3.59 & .95 \\
\hline Overall Health & 4.16 & .68 \\
\hline Mental -emotional health (MEH) & 4.23 & .75 \\
\hline Physical health (PH) & 4.04 & .82 \\
\hline
\end{tabular}

A Pearson's correlation statistical test was used to analyze the relationship between enrichment from both the work-to-family and family-to-work directions, health (mentalemotional, physical, overall) and demographics. Significance was determined at the $p<$ .05 level for all statistical analysis. Pearson's test revealed statistically significant relationships between work-family enrichment and all three health variables examined: mental-emotional (WFE, $r=.228$; FWE, $r=.393$ ), physical health (WFE, $r=.221$ ), overall health (WFE, $r=.228$; FWE, $r=.393$ ). Through this analysis, a stronger correlation is revealed in the family-to-work direction when compared to the work-tofamily direction (see Table 3).

Table 3. Intercorrelations Among Study Variables

\begin{tabular}{|l|l|l|l|l|l|l|l|l|l|l|l|l|l|l|l|l|l|}
\hline \multicolumn{1}{|c|}{ Variable } & $\mathbf{1}$ & $\mathbf{2}$ & $\mathbf{3}$ & $\mathbf{4}$ & $\mathbf{5}$ & $\mathbf{6}$ & $\mathbf{7}$ & $\mathbf{8}$ & $\mathbf{9}$ & $\mathbf{1 0}$ & $\mathbf{1 0 a}$ & $\mathbf{1 0 b}$ & $\mathbf{1 1}$ & $\mathbf{1 2}$ & $\mathbf{1 3}$ & $\mathbf{1 4}$ & $\mathbf{1 5}$ \\
\hline 1. Enrichment & -- & & & & & & & & & & & & & & & & \\
\hline 2. WFE & .87 & -- & & & & & & & & & & & & & & & \\
\hline 3. FWE & .88 & .54 & -- & & & & & & & & & & & & & & \\
\hline 4. WFD & .73 & .76 & .52 & -- & & & & & & & & & & & & & \\
\hline 5. WFA & .70 & .85 & .38 & .43 & -- & & & & & & & & & & & & \\
\hline 6. WFC & .75 & .87 & .45 & .49 & .62 & -- & & & & & & & & & & & \\
\hline 7. FWD & .69 & .42 & .80 & .49 & .23 & .32 & -- & & & & & & & & & & \\
\hline 8. FWA & .72 & .47 & .79 & .42 & .38 & .36 & .42 & -- & & & & & & & & & \\
\hline 9. FWEF & .73 & .43 & .85 & .36 & .30 & .40 & .56 & .47 & -- & & & & & & & & \\
\hline 10. Health & .35 & .23 & .39 & .22 & .18 & .17 & .33 & .31 & .32 & -- & & & & & & & \\
\hline a. MEH & .35 & .23 & .40 & .25 & .14 & .19 & .35 & .29 & .33 & .88 & -- & & & & & & \\
\hline b. PH & .21 & .13 & .24 & .08 & .15 & .09 & .17 & .20 & .20 & .87 & .56 & -- & & & & & \\
\hline 11. Work status & .10 & .09 & .11 & .08 & .05 & .08 & .13 & .06 & .08 & .01 & -.01 & .03 & -- & & & & \\
\hline 12. Age & .07 & .18 & -.06 & .08 & .19 & .16 & .05 & -.09 & -.09 & -.11 & -.01 & -.15 & -.12 & -- & & & \\
\hline 13. Gender & -.00 & -.05 & .04 & .02 & -.04 & -.09 & .12 & .02 & -.02 & -.16 & -.28 & -.02 & .24 & -.16 & -- & & \\
\hline 14. Children & .07 & .16 & -.03 & .12 & .11 & .15 & .06 & -.02 & -.09 & -.07 & -.02 & -.10 & -.10 & .70 & -.21 & -- & \\
\hline 15. Marital & -.03 & -.08 & .03 & -.02 & -.15 & -.03 & -.02 & .04 & .05 & .06 & .15 & -.03 & -.04 & .06 & -.33 & .22 & -- \\
\hline 16. Education & -.04 & -.09 & .01 & -.01 & -.11 & -.09 & -.01 & .01 & .02 & .09 & .08 & .08 & .02 & .03 & -.19 & .19 & .21 \\
\hline
\end{tabular}

$r \geq[.19], p<.05 ; r \geq[.24], p<.01 ; r \geq[.29], p<.001 ; \mathrm{n}=116$ 
Table 3 also reveals one significant correlation between age and work-to-family affect, but no other significant statistics were found between the core study constructs and the six demographic variables. Multiple regressions were used to analyze the relationship between work-family enrichment and demographics (i.e. work status, age, gender, number of children, marital status, and education level). Again, the only statistically significant correlation discovered was between work-to-family affect and age $(r=.192)$. The other variables had no predictive power.

The findings of this study should be viewed in light of its limitations. First, the sample size was small with only 116 participants. Second, the study only examined two stores in a single organization within one industry. Third, the instrument was a survey questionnaire and it did not ask or collect any in-depth and insightful responses from participants. A final limitation focuses on the demographic composition of the sample. Most of the participants in this study are male in the 21-30 year range working full-time and attending college. Because the sample consists mostly of men, the generalizability of the study to both genders is limited and suggests future research to examine these differences in more depth. Future research may reveal differences in the way men and women experience work-family enrichment, as well as the different ways they are able to gather resources that transfer in both work and family domains.

\section{Discussion}

As Carlson et al. (2006) and Greenhaus and Powell (2006) have argued, the findings of this study suggest that employees do perceive a positive connection between work and family. They believe (moderately to strongly) that work can enrich family and that family can enrich work. These results also suggest that enrichment exists in this sample from both the work-to-family and family-to-work direction. However, it is clear that the influence of family-to-work enrichment is stronger. This finding supports current research of Greenhaus and Powell (2006) also stating a substantially stronger family-towork relationship than work-to-family relationship. This means that family provides more resources to enrich work than does work provide for enriching family. The affect variable is of particular interest, with the mean from family-to-work being substantially higher (by over a full point, the difference between 2.72 to 3.92) compared to work-to-family affect. Again, affect refers to one domain providing a positive emotional state or attitude that assists in the other domain. In this sample participants perceive much greater positive influences coming from home with regard to affect or their emotional states.

This study also suggests that work-family enrichment and health may influence one another. Overall health and mental-emotional health were strongly correlated to enrichment in the family-to-work direction, suggesting that family participation supports the mental-emotional and overall health of an individual. It is important to note that this study did not examine the direction of this relationship. These findings also support those of Grzywacz and Bass (2003), Hanson et al. (2006), Grzywacz (2000), and Barnett and Baruch (1986), who also found positive health behaviors (lower mental illness, depression, and problem drinking; higher overall mental and physical health) are associated with simultaneous involvement in work and family roles. The current study 
only measured the employees' perceptions of health, not actual health. However, perceptions are an important measure of various dimensions of health and overall wellbeing; they have been used in many respected studies (e.g., Frone et al., 1997). Most of the previously health-related studies (e.g., Frone et al., 1997; Frone et al., 1996; Madsen et al., 2005; Major et al., 2002) have researched the relationship between workfamily conflict and stress with decreased wellbeing. This also supports the notion that employees who have lower levels of work-family enrichment also have lower perceptions of mental and physical health.

The limitations of this study, particularly the sample size, may have contributed to the lack of significant findings with regard to the various demographics studied in this research. As mentioned previously, the only relationship discovered was between workto-family affect and age. In other words, the older the participant, the more the more work involvement results in a positive emotional state or attitude. It is difficult to posit a specific reason for this finding. It could be that older employees have worked in these branches longer and have stayed longer because the job brings them satisfaction. We did not ask how long subjects were employed at their jobs so this may or may not be the case. It may also be that younger employees have fewer or no children. The age and number of children has been shown to affect work-to-family conflict. Intuitively then, having fewer or no children (particularly young children) may influence employees' perceptions of positive or negative emotional states or attitudes. A final explanation may be that with age and experience come insight and reflective skills that may result in increased abilities to bring more positive work-related feelings and attitudes home. This finding is generally supported by Grzywacz and Marks (2000) research findings that older men experienced more positive spillover from work-to-family. However, they also found the same from family-to-work, which did not appear in this study. Some past literature also reported gender differences, but the current study found none. Again this may be related to small sample size and lower number of female participants.

\section{Conclusions}

This study offers contributions to the management and human resource development literature. First, it provides support for some of the existing literature that presents new constructs for consideration in this area. Second, the concept of work-family enrichment is in its infancy with regard to research and literature. Carlson et al.'s (2006) 18-item instrument was published in 2006 and, at the time of this research, no other researchers had published studies utilizing the newly created scale. This study supports the validity of the scale, and its continued use in measuring these new constructs. Third, it supports the premise that (as with work-family conflict) work-family enrichment and health are complex phenomena and factors that influence them need to be explored in both research and practice. Finally, although cause-effect relationships can only be suggested from these findings, practitioners may begin to consider this information as they assess, design, and evaluate new and existing workplace programs or initiatives for the work-life realm. 
The results of this study suggest recommendations for practitioners. First, as training and development programs and organization development interventions are designed, knowledge of work-family enrichment will aid in understanding the types of resources and skills employees are able to utilize to increase performance in their work and family roles. This understanding gives practitioners additional tools to strategically utilize workfamily enrichment to achieve organizational goals. Effective interventions based on work-family enrichment may have positive implications for career development, retention, and job satisfaction, which are linked to the increase of individual and organizational effectiveness. Second, many organizational leaders consider work-family enrichment interventions as nonessential or unrelated to the bottom line. Yet it is clear that there is a relationship between work-family enrichment and individual health. Nevertheless, in today's workplaces health is seen as directly influencing the bottomline. Leaders and managers need to be educated about the relationships among employee productivity/performance (bottom line) and the workplace, psychological, and behavioral correlates that influence them (including health and work-life issues). Overall, interventions focused on these relationships should be considered. This research can also provide support for human resource professionals who are writing proposals for such initiatives.

There are several recommendations for future research. First, research needs to be continued to determine the causality of work-family enrichment construct with other variables; specifically, an investigation into employees' perceptions of a stronger link between family-to-work enrichment and a variety of possible moderating and influential factors may be helpful. This research only addressed a few. Understanding what factors in work and family life influence enrichment could be valuable to employees as they strive to find balance in these roles. Organizations could put themselves in a position to harvest these moderators and create a workplace of constant improvement and efficiency while promoting retention and employee job satisfaction. Second, further investigation into the role of gender and work-family enrichment (Greenhaus \& Powell, 2006) is also needed as well as a deeper understanding of the relationship between age and work-family enrichment. As previously mentioned, gender findings in the workfamily interface tend to be inconsistent, which emphasizes the need for better understanding. Future research may reveal important distinctions in the way men and women experience work-family enrichment. Third, future research should also focus on other demographic variables which may be mediating influences in the work-family interface. A deeper understanding of the role of children (number and ages) and partner support in work-family enrichment would be helpful. Qualitative research exploring the specific supportive behaviors that are linked to higher work-family enrichment would be valuable. Finally, research is also needed on the types of different resources (i.e., skills and perspectives, psychological and physical, social-capital, flexibility, and material resources) that provide the greatest work-family enrichment for individuals. The identification of specific components and characteristics of these resources would be particularly meaningful for practitioners as they consider specific intervention and implementation strategies to help employees integrate work and family more effectively. 


\section{References}

Allen, T. D., Herst, D. E., Bruck, C. S., \& Sutton, M. (2000). Consequences associated with work-family conflict: A review and agenda for future research. Journal of Occupational Health Psychology, 5(2), 278-308.

Barnett, R. C., \& Baruch, G. K. (1986). Role quality, multiple role involvement, and psychological well-being in midlife women. Journal of Personality and Social Psychology, 51(3), 578-585.

Carlson, D. S., Kacmar, M. K., Wayne, J. H., \& Grzywacz, J. G. (2006). Measuring the positive side of the work-family interface: Development and validation of a work-family enrichment scale. Journal of Vocational Behavior, 68(1), 131-164.

Carlson, D. S., Kacmar, M. K., \& Williams, L. J. (2000). Construction and validation of a multidimensional measure of work-family conflict. Journal of Vocational Behavior, 56(2), 249-276.

Crouter, A. (1984). Participative work as an influence on human development. Journal of Applied Developmental Psychology, 5(1), 71-90.

Frone, M. R. (2000). Work-family conflict and employee psychiatric disorders: The National Comorbidity Survey. Journal of Applied Psychology, 85(6), 888-895.

Frone, M. R., Russell, M., \& Barnes, G. M. (1996). Work-family conflict, gender and health related outcomes: A study of employed parents in two community samples. Journal of Occupational Health Psychology, 1(1), 57-69.

Frone, M. R., Russell, M., \& Cooper, M. L. (1997). Relation of work-family conflict to health outcomes: A four-year longitudinal study of employed parents. Journal of Occupational and Organizational Psychology, 70(4), 325-335.

Hanpachern, C., Morgan, G. A., \& Griego, O. V. (1998). An extension of the theory of margin: A framework for assessing readiness for change. Human Resource Development Quarterly, 9(4), 339-350.

Hanson, G. C., Hammer, L. B., \& Colton, C. L. (2006). Development and validation of a multidimensional scale of perceived work-family positive spillover. Journal of Occupational Health Psychology, 11(3), 249-265.

Greenhaus, J. H., \& Beutell, N. J. (1985). Sources of conflict between work and family roles. Academy of Management Review, 10(1), 76-88.

Greenhaus, J. H., \& Powell, G. N. (2006). When work and family are allies: A theory of work-family enrichment. Academy of Management Review, 31(1), 72-92. 
Grzywacz, J. G., \& Bass, B. L. (2003). Work, family, and mental health: Testing different models of work-family fit. Journal of Marriage and Family, 65(1), 248-262.

Grzywacz, J. G. (2000). Work-family spillover and health during midlife: Is managing conflict everything? American Journal of Health Promotion, 14(14), 236-243.

Grzywacz, J. G., \& Marks, N. F. (2000). Family, work, work-family spillover and problem drinking during midlife. Journal of Marriage and the Family, 62(2), 336-348.

Madsen, S. R., John, C. R., \& Miller, D. (2005). Work-family conflict and health: A study of workplace, psychological, and behavioral correlates. Journal of Behavioral and Applied Management, 6(3), 225-247.

Major, V. S., Klein, K. J., \& Ehrhart, M. G. (2002). Work time, work interference with family, and psychological distress. Journal of Applied Psychology, 87(3), 427-436.

Parasuraman, S., \& Greenhaus, J. H. (1997). The changing world of work and family. In S. Parasuraman \& J. H. Greenhaus (Eds.), Integrating work and family: Challenges and choices for a changing world (pp. 3-14). Westport: Praeger.

Rothbard, N. (2001). Enriching or depleting? The dynamics of engagement in work and family roles. Administrative Science Quarterly, 46(4), 655-684.

Sieber, S. D. (1974). Toward a theory of role accumulations. American Sociological Review, 39(4), 567-578.

U.S. Department of Labor. (1999). Futurework: Trends and challenges for work in the 21st century. Washington DC: U.S. Department of Labor. 